\title{
Finite element analysis of bending performance of basalt fiber reinforced concrete beam
}

\author{
Cong Wang ${ }^{1}$, Changchun Pei ${ }^{1, a, *}$ \\ ${ }^{1}$ Department of Structural Engineering,College of Engineering,YanbianUniversity, Yanji, 133002, \\ China \\ ${ }^{a, *}$ Corresponding author: peicc@ybu.edu.cn
}

\begin{abstract}
Keywords: basalt fiber, reinforcement ratio, finite element analysis, recycled concrete beam,
\end{abstract} bending performance.

\begin{abstract}
In this paper, through different reinforcement ratio and basalt fiber content, ultimate bearing capacity, stress-strain of regenerated concrete beam of basalt fiber were studied. As the result, basalt fiber reinforced the flexural performance of the recycled concrete beam obviously , the proper ratio of reinforcement can obviously enhance the flexural behavior of the basalt fiber recycled concrete beam too. Through simulation analysis, when the basalt fiber content is $2 \mathrm{~kg} / \mathrm{m}^{3}$, the bending strength of basalt fiber regenerated concrete beam is the most obvious. The formula of yield bearing capacity about basalt fiber regenerated concrete beam fiber is simulated , the error between the calculated value and the simulated value is within $5 \%$.
\end{abstract}

\section{Introduction}

With the rapid development of the construction industry, a large number of buildings were demolished and rebuilt, the occurrence of a large amount of construction waste, which accounts for most of the waste concrete. Rational treatment of waste concrete is an important way to efficient use of resources and sustainable development. Xiao Jianzhuang and other research data show that ${ }^{[1,2,3,4]}$ :The compressive strength, Splitting tensile strength and fatigue strength decrease gradually with the increase of the replacement ratio of recycled aggregate, and the maximum crack width and the number of cracks increase step by step. Therefore, the domestic and foreign scholars ${ }^{[5,6]}$ use the method of adding fiber in concrete to improve the strength, crack resistance and ductility of recycled concrete, and get some positive results, but due to high temperature stability and chemical stability, its wide application certain restrictions. In recent years, it has been found that basalt fiber has the advantages of high temperature resistance, chemical stability and good compatibility with silicate materials.

Therefore, this change of recycled aggregate concrete and basalt fiber content reinforcement ratio, finite element analysis of initial cracking load, yield load, stress - strain relations bending performance, regenerative expand aggregate concrete should provide a reference.

\section{Design}

In this paper, three levels of basalt fiber content $0 \mathrm{~kg} / \mathrm{m}^{3}, 2 \mathrm{~kg} / \mathrm{m}^{3}, 4 \mathrm{~kg} / \mathrm{m}^{3}$ and $0.96 \%, 1.25 \%, 1.43 \%$ of reinforcement ratio were changed in the recycled aggregate concrete. A total of 10 beams were designed. Beam length are $1500 \mathrm{~mm}$, the net cross $-1200 \mathrm{~mm}$, cross-section size are $150 \mathrm{~mm} \times$ 250mm. Concrete using C35, longitudinal steel beams are HRB335 with diameter of 14mm and $16 \mathrm{~mm}$, erecting tendons and stirrups are HPB300 with diameter of $8 \mathrm{~mm}$. Reinforcement of the specimen shown in figure 1. By using finite element method to analyze the initial cracking load, yield load and load-span deflection relationship of the beam, comparative analysis the bending performance of basalt fiber reinforced concrete beam. The detailed scheme design is shown in Table 1. 


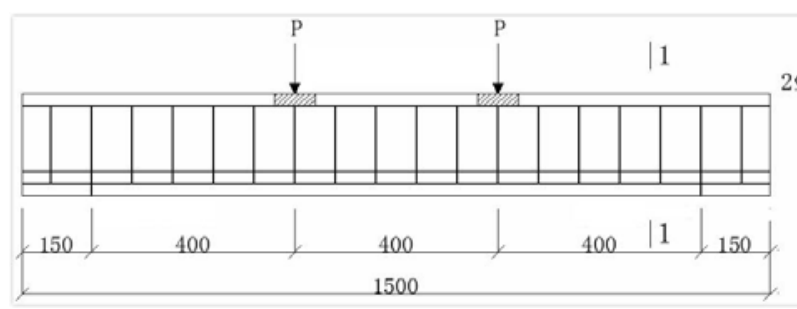

(a) floor plan

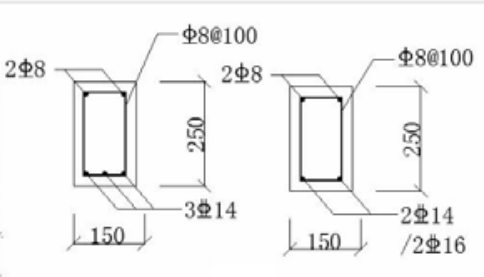

(b)1-1 sectional view

Fig. 1 The structure diagram of the specimen (unit: $\mathrm{mm}$ )

Tab.1 The parameters of the test beam

\begin{tabular}{ccccccc}
\hline $\begin{array}{c}\text { Specimen } \\
\text { Number }\end{array}$ & $\begin{array}{c}\text { Recycled } \\
\text { aggregate } \\
\text { replacement rate }\end{array}$ & $\begin{array}{c}\text { Basalt fiber } \\
\text { content(kg/m }\left(\mathrm{m}^{3}\right)\end{array}$ & $\begin{array}{c}\text { Reinforcement } \\
\text { ratio(\%) }\end{array}$ & $\begin{array}{c}\text { Axial } \\
\text { compressive } \\
\text { strength (MPa) }\end{array}$ & $\begin{array}{c}\text { Splitting } \\
\text { tensile } \\
\text { strength } \\
\text { (Mpa) }\end{array}$ & $\begin{array}{c}\text { Elastic } \\
\text { Modulus } \\
\text { (Gpa) }\end{array}$ \\
\hline $\mathrm{NC}$ & 0 & 0 & 1.25 & 33.50 & 3.03 & 36.40 \\
$\mathrm{~B}_{0} \mathrm{~S}_{1}$ & 40 & 0 & 0.96 & 31.10 & 2.77 & 37.20 \\
$\mathrm{~B}_{0} \mathrm{~S}_{2}$ & 40 & 0 & 1.25 & 31.10 & 2.77 & 37.20 \\
$\mathrm{~B}_{0} \mathrm{~S}_{3}$ & 40 & 0 & 1.43 & 31.10 & 2.77 & 37.20 \\
$\mathrm{~B}_{2} \mathrm{~S}_{1}$ & 40 & 2 & 0.96 & 30.80 & 2.83 & 35.60 \\
$\mathrm{~B}_{2} \mathrm{~S}_{2}$ & 40 & 2 & 1.25 & 30.80 & 2.83 & 35.60 \\
$\mathrm{~B}_{2} \mathrm{~S}_{3}$ & 40 & 2 & 1.43 & 30.80 & 2.83 & 35.60 \\
$\mathrm{~B}_{4} \mathrm{~S}_{1}$ & 40 & 4 & 0.96 & 31.70 & 3.00 & 35.90 \\
$\mathrm{~B}_{4} \mathrm{~S}_{2}$ & 40 & 4 & 1.25 & 31.70 & 3.00 & 35.90 \\
$\mathrm{~B}_{4} \mathrm{~S}_{3}$ & 40 & 4 & 1.43 & 31.70 & 3.00 & 35.90 \\
\hline
\end{tabular}

Note: In the sample number, the letter means:

1) NC: indicates the use of $100 \%$ natural aggregate, not mixed with basalt fiber concrete;

2) $B_{x} S_{y}: B x S y$ is recycled concrete using $40 \%$ recycled aggregate. Among them, $B$ is representative of basalt fiber, and the subscript $x$ value represents the amount of basalt fiber $\left(\mathrm{kg} / \mathrm{m}^{3}\right) . \mathrm{S}$ is represents the steel bar, and the 1, 2, 3 of the subscript y value respectively represent the steel reinforcement ratio of $0.96 \%$, and $1.43 \%$, respectively.

\section{The Establishment of FEM}

options of the finite element types.

The reinforced concrete beam by using the separation model, which adopts SOLID 65 concrete unit, reinforcement and stirrup are used LINK 8 unit.

\section{Selection of Material Constitutive Relation}

The typical constitutive relationship of ordinary concrete is studied by Professor Guo zhenhai ${ }^{[7]}$, that is:

$$
y=\left\{\begin{aligned}
2.2 x-1.4 x^{2}+0.2 x^{3}, & x \leq 1 \\
\frac{x}{0.4 \cdot(x-1)^{2}+x}, & x>1
\end{aligned}\right.
$$

The expression of the rising curve of basalt fiber reinforced concrete ${ }^{[8]}$ :

$$
\mathrm{y}=\alpha \mathrm{x}+(3-2 \alpha) x^{2}+(\alpha-2) x^{3}
$$

The influence of basalt fiber is considered: when the fiber content is $0,2 \mathrm{~kg} / \mathrm{m} 3,4 \mathrm{~kg} / \mathrm{m} 3$,the parameters of the rising segment are selected:

$$
\alpha=0.0348 \times M_{B F}+1.876
$$

The expression of the constitutive equation of basalt fiber reinforced concrete ${ }^{[8]}$ :

$$
\mathrm{y}=\frac{\mathrm{x}}{\beta(x-1)^{2}+x}
$$

The influence of basalt fiber is considered: when the fiber content is $0,2 \mathrm{~kg} / \mathrm{m}^{3}, 4 \mathrm{~kg} / \mathrm{m}^{3}$, the value of the descending segment was selected:

constitutional relation of reinforcement

$$
\beta=-0.0396 \times M_{B F}+2.000
$$


The elastic plastic model of basalt fiber reinforced concrete beam is used to simplify the model:

$$
\sigma_{s}= \begin{cases}E_{S} \varepsilon_{S} & \varepsilon_{S} \leq \varepsilon_{y} \\ f_{y} & \varepsilon_{S}>\varepsilon_{y}\end{cases}
$$

\section{Finite element simulation results and analysis}

\section{The different reinforcement ratio of flexural properties of recycled concrete}

Cracking load and ultimate load of recycled concrete beams with different reinforcement ratio

Figure 2 is the blending rate of $40 \%$ recycle d aggregate under the condition of different reinforcement ratio of initial cracking load of recycled concrete beams and yield load diagram. As can be seen from the figure, with the increase of reinforcement ratio, the initial cracking load and yield load of the recycled concrete beam are increasing. The results show that the increase of reinforcement ratio can effectively improve the initial cracking load and yield load of recycled concrete beams. However, both the initial cracking load and yield load are lower than that of the natural concrete beam with the same reinforcement ratio, this is because the recycled coarse aggregate with cracks, water absorption rate, residual fine around original cement slurry and other factors of the initial crack load and yield load.

Equivalent stress cloud

Figure 3 shows the equivalent crack stress of the recycled concrete beam. It can be seen from the graph that the maximum compressive stress occurs in the upper pressure zone in the initial stage. With the increase of the reinforcement ratio, the maximum compressive stress is also increased. But the increase is not particularly obvious, indicating that the increase of reinforcement ratio of recycled concrete beam of the initial cracking stress is not very obvious.

Figure 4 shows the equivalent yield stress plots of recycled concrete beams with different reinforcement ratios. According to the graph, the maximum compressive

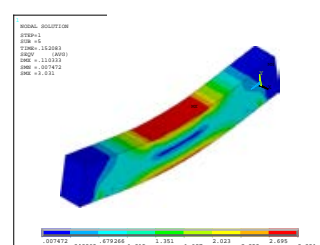

(a) $\mathrm{NC}$

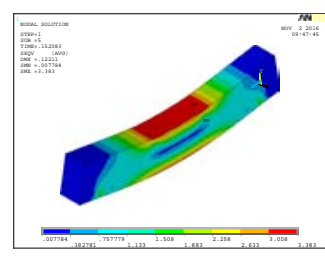

(c) $\mathrm{B}_{0} \mathrm{~S}_{2}$

Fig.3 Different reinforcement ratio of recycled concrete beams cracking equivalent stress cloud

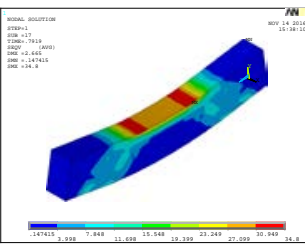

(a) $\mathrm{NC}$

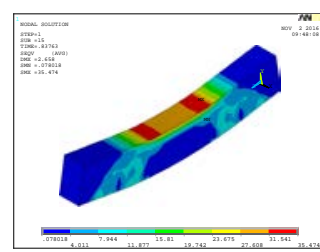

(c) $\mathrm{B}_{0} \mathrm{~S}_{2}$

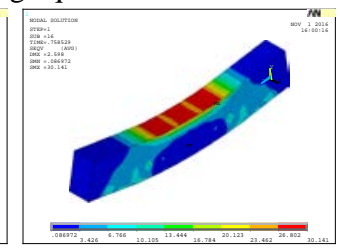

(b) $\mathrm{B}_{0} \mathrm{~S}_{1}$

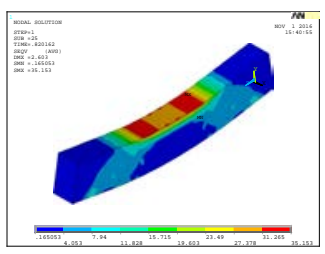

(d) $\mathrm{B}_{0} \mathrm{~S}_{3}$
Fig.4 Different reinforcement ratio of recycled concrete beams equivalent yield stress cloud stress occurs in the upper compression zone of the beam in the yielding stage, this is because when the steel yield before and after the compression of concrete compressive stress growth rate faster. With the increase of the reinforcement ratio, the maximum compressive stress gradually increases. Among them, when the reinforcement ratio is $1.43 \%$, ratio of reinforcement ratio as the maximum compressive stress decreased $1.25 \%$.

\section{The bending resistance of recycled concrete beams strengthened with basalt fiber}

Cracking load and ultimate load of recycled concrete beams with different ratios of basalt fiber recycled concrete beams with different ratios of basalt fiber

Figure 5 shows the initial cracking load and yield load of the recycled concrete beams with different fiber content when the recycled aggregate content is $40 \%$ and the reinforcement ratio is $1.25 \%$. As can be seen from the figure, with the increase of the fiber content, the cracking load and yield load of the basalt fiber reinforced concrete beam are gradually increased, because of its high tensile strength and high elongation. Fiber mixed into concrete, reduce the production of cracks, and limit 
the expansion of cracks of cement base material under external force, the fibers are resistant to external forces across the fracture, and improve the flexural strength of the concrete tensile strength, toughness increased.

Equivalent stress cloud

Figure 6 shows the equivalent crack stress of the regenerated concrete beam of the basalt fiber. It can be seen from the figure that with the increase of fiber incorporation, the maximum compressive stress in the initial cracking phase increases obviously and the cracks appear late, indicating that the tensile strength of the recycled concrete beam is obviously enhanced by adding the basalt fiber.

Figure 7 shows the equivalent crack stress of the basalt fiber regenerated concrete beam. From the figure shows that the maximum stress appears in the loading region of the beam, the incorporation of the yield load of recycled concrete beams after fiber compared with ordinary recycled concrete beam is too large, and with the increase of fiber volume, yield load gradually increased, destruction of late. The results show that the basalt fiber can improve the yield strength of the recycled concrete beam and improve the flexural performance of the beam.

\section{Contrast Analysis of Load - Deflection Curve}

Figure 8 shows the load-span deflection curve of regenerated concrete beams with basalt fiber. It can be seen from the figure that the before the cracking, the variation trend of load - span deflection of ordinary concrete beam is the same. It can be seen that the influence of the reinforcement ratio on the tensile and flexural properties of the concrete beams is not obvious. With the increase of the content of basalt fiber, the tensile and flexural properties of concrete beams are gradually increased under the same load. This is because the basalt fiber can effectively impede the concrete beam crack development, enhance the toughness o f concrete beams, so that the deflection of recycled concrete beams to reduce.

\section{Simulation formula for yield bearing capacity of regenerated concrete beams with basalt fiber}

In order to better apply to the actual project, it is convenient to join with the calculation formula of normal section bearing capacity of ordinary reinforced concrete flexural members. The calculation formula of the normal section bearing capacity of recycled concrete beams is established based on ordinary reinforced concrete beams.

According to the specification, normal section bearing capacity formula of ordinary concrete:

$$
M_{u}=f_{y} A_{s}\left(h_{0}-\frac{f_{y} A_{s}}{2 \alpha_{1} f_{c} b}\right)
$$

$f_{y}$ is the design value of tensile strength, $A_{s}$ is sectional area of reinforced zone in tension zone, $h_{0}$ 
is effective height of section, $b$ is section width, $\mathrm{f}_{\mathrm{c}}$ is axial compressive strength of concrete. Because the ultimate bearing capacity of ordinary concrete beam is almost the same as that of recycled concrete, the ultimate bearing capacity of recycled concrete beam can be calculated by the formula of normal section bearing capacity of ordinary concrete beam.

Taking into effect of basalt fiber on the basalt fiber reinforced concrete beam strengthening effect of the normal cross-section, this paper assumes the following:

$$
M_{u 1}=\left(1+k_{B F} \lambda_{B F}\right) M_{u}
$$

$\mathrm{M}_{\mathrm{u}}$ is ultimate bearing capacity of ordinary concrete beam, $\mathrm{M}_{\mathrm{u} 1}$ is maximum bending moment of normal section of basalt fiber recycled concrete beam, $\mathrm{k}_{\mathrm{BF}}$ is basalt fiber reinforcement coefficient, $\lambda_{\mathrm{BF}}$ is basalt fiber content characteristic value. The following is derived $\mathrm{k}_{\mathrm{BF}}$, test beam bending moment is $\mathrm{M}=\mathrm{P} \times \mathrm{L}$, since all test beams are loaded at equal distances, the limit load $\mathrm{P}$ may be used in place of $\mathrm{M}$ to derive $\mathrm{k}_{\mathrm{BF}}$.

Derivation of basalt fiber reinforced coefficient $\mathrm{k}_{\mathrm{BF}}$ :

$$
M_{u 1}=\left(1+k_{B F} \lambda_{B F}\right) M_{u}
$$

Take beam $\mathrm{B}_{2} \mathrm{~S}_{1}$ as an example, according to the physical properties of basalt fiber, basalt fiber length of $20 \mathrm{~mm}$, diameter of $0.015 \mathrm{~mm} . \lambda_{\mathrm{BF}}=\frac{\rho_{\mathrm{g}} \mathrm{l}_{\mathrm{BF}}}{\mathrm{d}_{\mathrm{BF}}}=0.1 \% \times 1333=1.33, \mathrm{M}_{\mathrm{u}}=121.36 \mathrm{kN}$, $\mathrm{M}_{\mathrm{u} 1}=123.23 \mathrm{kNto}$ equation (8) , get $\mathrm{k}_{\mathrm{BF}}=0.011$; Similarly get the $\mathrm{B}_{2} \mathrm{~S}_{2}, \mathrm{~B}_{2} \mathrm{~S}_{3}, \mathrm{~B}_{4} \mathrm{~S}_{1}, \mathrm{~B}_{4} \mathrm{~S}_{2}$ and $\mathrm{B}_{4} \mathrm{~S}_{3}$ of $\mathrm{k}_{\mathrm{BF}}$. The average value of $\mathrm{k}_{\mathrm{BF}}$ is 0.031

So the basalt fiber reinforced concrete beam flexural capacity of the formula is as follows:

\section{Comparison of calculated and simulated values}

$$
M_{u 1}=\left(1+0.031 \lambda_{B F}\right) M_{u}
$$

Figure 9 shows the comparison of the calculated and simulated values about the basalt fiber regenerated concrete beam. It can be seen from the figure, the calculated value and the simulated value of the error are less than $5 \%$, to meet the practical application of the calculation accuracy.

\section{conclusion}

In this paper, ANSYS finite element analysis is used to study the influence of different reinforcement ratio and fiber content on the cracking load and ultimate load of the beam under the condition that the replacement ratio of recycled aggregate is $40 \%$. Research results show that:

(1)The yield load of basalt fiber reinforced concrete beam increases obviously with the increase of reinforcement ratio.

(2)The incorporation of basalt fiber restricts the generation and expansion of beam crack, reduces the deflection of beam, improves its bending resistance, and also improves its yield strength. The results show that when the basalt fiber content is $2 \mathrm{~kg} / \mathrm{m} 3$, the cracking load and ultimate load reach the maximum value, which are $29.8 \mathrm{kN}$ and $178.3 \mathrm{kN}$ respectively.

(3)Based on the calculation formula of flexural bearing capacity of normal reinforced concrete beams, the calculation formula of flexural capacity of reinforced concrete beams is proposed. The average error is less than $5 \%$ in comparison with the simulated data.

\section{References}

[1] Xiao Jianzhuang, Lan Yang, Experimental study on flexural performance of recycled concrete beams,j. Special structure. 2006, 23(1): 9-12.

[2] Cui Zhenglong, Tong Huabin, Wu Xiangyu, Study on the influence of morphology and properties of recycled coarse aggregate on mechanical properties of concrete,j. Bulletin of the Chinese Ceramic Society, 2014,33 (9): 2429-2433. 
[3] Sumit Arora, S.P. Singh. Analysis of flexural fatigue failure of concrete made with 100\% CoarseRecycled Concrete Aggregates,J. Construction and Building Materials,2015,27 (12):782-791

[4] Won-Chang Choi, Hyun-Do Yun. Long-term deflection and flexural behavior of reinforced concrete beams with recycled aggregate, J.Materials and Structure,2013,53:742-750.

[5] Xu Chengkai, Pei Changchun, On raw material control and proportion ratio design of draining asphalt mixture,j. Shanxi Architecture, 2016,42(2):109-111

[6] Shi Yin, Rabin Tuladhar, Tony Collister. Post-cracking performance of recycled polypropylene fibre in concrete[J]. Construction and Building Materials,2015, 15(10):1069-1077

[7] Guo Zhenhai, Shi Xudong, Principle and analysis of reinforced concrete,m. tsinghua university press, 2003

[8] Chen Meng, The Main Performance And Stress-Strain Relationship Of Basalt Fiber Rubber Recycied Concrete,d. North China University of Water Resources and Electric Power,2015. 